\title{
Regulation of TNFRSF and innate immune signalling complexes by TRAFs and clAPs
}

\author{
$\mathrm{J} \mathrm{Silke}^{\star, 1}$ and R Brink ${ }^{2}$
}

There have been a number of recent discoveries relating to the functions of inhibitors of apoptosis (IAPs) and TNF receptor-associated factors (TRAFs) in regulating signalling from TNF receptor superfamily (TNFRSF) members and some tantalizing glimpses into a wider area of influence, that of innate immune signalling. Discoveries relating to the function of these ubiquitin E3 ligases in regulating signalling from the eponymous member of the family, TNF-R1, are dealt with superbly in a separate review by Wertz and Dixit and so we will confine our discussion to the subset of the TNFRSF that does not contain a death domain (DD). In line with the available data we will divide the review into two parts, the first is restricted to the role of TRAFs 2 and 3 and cIAPs in regulating TNFRSF signalling, whereas the second will be more speculative, asking what role IAPs and TRAFs have in innate immune signalling.

Cell Death and Differentiation (2010) 17, 35-45; doi:10.1038/cdd.2009.114; published online 14 August 2009

\section{TRAFs and clAPs}

The first members of the TRAF family, TRAF1 and TRAF2, were identified through their direct recruitment to TNF-R2 ${ }^{1}$ and the family now comprises at least six members (TRAF1-6). TNF-R2 is a member of the TNFRSF and this superfamily of receptors has key roles in the development and regulation of the immune system. Following ligand binding to the extracellular domains, the receptors assemble a signalling complex on their intracellular portion that transduces signals intracellularly. Of the 27,20 receptors have TRAF binding sequences in their intracellular domains and some of the remaining 7 can recruit TRAFs indirectly. Though they undoubtedly are involved in regulating TNFRSF signalling, ${ }^{2,3}$ we will only peripherally mention TRAF1 and TRAF6 (see Wu and Arron ${ }^{4}$ for a recent review) due to space constraints and will confine our discussion to TRAFs 2 and 3 . It is natural to discuss these TRAFs and clAPs together: clAPs were first described as binding partners of TRAF2, indirectly recruited to TNF-R2 by TRAF2 ${ }^{5}$ and this was no chance association because TRAF2 and CIAP1 frequently function together in many different pathways. Recently the importance of interactions betweens ClAPs/TRAF2 and TRAF3 has also been demonstrated, as we will discuss.

In a way, however, this close association is puzzling, because both TRAF2 and clAPs are really interesting new gene (RING) domain containing E3 ligases. The RING domains allow TRAF2 and CIAP1 to recruit ubiquitin-conjugating E2 enzymes (UBCs) to substrates that thereby become ubiquitylated. So why should such intimate partners as CIAPs and TRAFs have the same molecular function? Or if we wanted to pose this question in an even more pointed manner, why are different RING-containing TRAFs recruited to the same receptors? It would be simple if these enzymes in fact performed different modifications, with for example TRAF2 promoting K63 ubiquitin modification ${ }^{6}$ and clAPs promoting the formation of K48-linked ubiquitin chains. ${ }^{7}$ Structural differences in the RINGs of TRAFs and clAPs that could allow them to promote the recruitment of different E2 enzymes make this a tenable hypothesis. ${ }^{8}$ However, although there is some evidence that this might be part of the story, at least in vitro, clAP1 appears to be capable of generating many different types of ubiquitin chain including both K48 and K63. ${ }^{9,10}$ Another explanation for the recruitment of both proteins is that TRAF2 RING targets different substrates to CIAP RING and there is some evidence that TRAF2 RING may be required for c-Jun $\mathrm{N}$-terminal kinase (JNK) signalling, for example. The main difficulty in trying to solve this simple puzzle is that TRAF2 is required to recruit clAPs to many of the TNF superfamily (TNFSF) receptors. Therefore a TRAF2 knockout prevents cIAP recruitment and function at TNFSF receptors. It is possible therefore that the main role of TRAF2 is to recruit clAPs in TNFSF signalling and its RING activity is dispensable. ${ }^{11,12}$ Yet another potential scenario is that TRAF2 RING and cIAP RINGs must heterodimerize to function and there are examples of such heterodimerization, albeit not for clAPs and TRAFs. ${ }^{13}$ An approach to this question will be to reconstitute knockout cells with TRAF2 that can not interact with clAPs, or clAPs that can not interact with TRAF2,${ }^{14}$ but

\footnotetext{
${ }^{1}$ Department of Biochemistry, La Trobe University, Kingsbury Drive, Melbourne, Victoria, Australia and ${ }^{2}$ Garvan Institute of Medical Research, 384 Victoria Street, Darlinghurst, New South Wales, Australia

*Corresponding author: J Silke, Department of Biochemistry, La Trobe University, 4th Floor, LR Reid Building, Melbourne, Victoria 3086, Australia.

Tel: + 6139479 1270; Fax: + 6139479 2467; E-mail: j.silke@latrobe.edu.au

Keywords: apoptosis; clAPs; kinases; RIPK1; NIK; TNF

Abbreviations: ASK, apoptosis signal-regulating kinase; BAFF, B-cell-activating factor; IAP, inhibitor of apoptosis; IKK, inhibitor of nuclear factor $\kappa$-B kinase; JNK, c-Jun N-terminal kinase; NEMO, NF- $\kappa$-B essential modulator; RING, really interesting new gene; RIPK, receptor-interacting serine/threonine-protein kinase; TNFRSF, TNF receptor superfamily; TNFSF, TNF superfamily; TRAF, TNF receptor-associated factor; TWEAK, TNF-related weak inducer of apoptosis; UBC, ubiquitinconjugating enzyme E2

Received 31.3.09; revised 04.6.09; accepted 30.6.09; Edited by G Melino; published online 14.8 .09
} 
the ultimate answer should prove interesting. Whatever the final answer, it is worth bearing in mind throughout the review that a TRAF2 knockout may have a phenotype because of a failure to recruit clAPs. Even over-expression of a TRAF2 RING protein has the potential to interfere in the same manner, by generating a pool of TRAF2 that is not bound to clAPs because of the limited supply of clAPs.

\section{TNFSF and NF- $\kappa$ B}

TNF receptor superfamily members contain one or several cysteine-rich domains in their extracellular portion and bind to ligands of the TNFSF. The degree of homology in these domains is quite weak and one receptor, FN14, was only recognized as a TNFRSF member when it was discovered that it bound the TNF-like ligand, TNF-related weak inducer of apoptosis (TWEAK). ${ }^{15}$ The TNFRSF has key functions in the development and regulation of the immune system and knockout mice of different family members usually have some form of immunopathology. ${ }^{16-18}$ TNFSF ligands frequently activate $\mathrm{NF}-\kappa \mathrm{B}$ and loss of this $\mathrm{NF}-\kappa \mathrm{B}$ response is likely to contribute to immune dysfunction. Furthermore, loss of NF- $\kappa \mathrm{B}$ signalling, for example in inhibitor of nuclear factor $\kappa$-B kinase (IKK) knockouts, mimics some of the effects seen in TNFSF knockouts. ${ }^{18}$ The complexities of NF- $\kappa \mathrm{B}$ signalling are therefore discussed before we discuss the functions of TRAFs and clAPs in regulating signalling from the TNFRSF.

Activation of NF- $\kappa$ B has been described in terms of canonical and non-canonical pathways. In this scheme, the canonical NF- $\kappa$ B pathway is defined by the liberation of RelAcontaining heterodimers from the inhibitory $\mathrm{I}_{\kappa} \mathrm{Bs} ; \mathrm{I}_{\kappa} \mathrm{B} \alpha, \mathrm{I}_{\kappa} \mathrm{B} \beta$ and $I_{\kappa} \mathrm{B} \varepsilon$, effected by proteasomal degradation of the $I_{\kappa} \mathrm{Bs}$. Signalling through receptors such as TNF-R1 results in formation of a platform that brings together IKK1/IKK2 and TAK1. TAK1 is believed to phosphorylate and activate IKK2 which is then able to phosphorylate $\mid \kappa B s$. Phosphorylation of $\mathrm{I} \kappa \mathrm{B} \alpha$ causes recruitment of an $\mathrm{E} 3$ ligase, $\mathrm{SCF}_{\beta \mathrm{TrCP}}$, that $\mathrm{K} 48$ ubiquitylates $\mathrm{I}_{\kappa} \mathrm{B} \alpha$ resulting in its rapid recruitment to, and degradation by, the proteasome. The liberated RelA heterodimers are thereby freed to enter the nucleus and promote transcription through $\kappa \mathrm{B}$ containing promoters and enhancers. Once liberated, RelA can be phosphorylated and acetylated, which may further alter its transcriptional activity but the physiological importance of these modifications still needs to be verified. ${ }^{19}$ The primary mediator of canonical $\mathrm{NF}-\kappa \mathrm{B}$ function in many cell types appears to be RelA/p50. ${ }^{16}$

Conversely, the non-canonical, or alternative, NF- $\kappa$ B pathway is most frequently used to describe IKK1 phosphorylation of $\mathrm{p} 100$ that results in processing of the inhibitory C-terminal domain of the p52 precursor, NF- $\kappa$ B2 p100, by limited proteasome-mediated proteolysis. ${ }^{20}$ Co-translational processing has been reported to be required for generation of p52 20,21 at least in response to LPS and the TNFSF ligands CD40, LT $\alpha_{1} \beta_{2}$ and LIGHT. Other TNFSF ligands, such as TWEAK, RANK-L and B-cell-activating factor (BAFF) and receptors such as $L T \beta R$, have also been described to activate $\mathrm{NF}-\kappa \mathrm{B} 2$ processing and thereby free $\mathrm{p} 52 /$ RelB dimers to enter the nucleus. ${ }^{22,23}$

Recently, however it has been proposed that $\mathrm{p} 100 / \mathrm{p} 100$ dimers are able to act as an $I_{\kappa} \mathrm{B}$-like molecule, called $\mathrm{I}_{\kappa} \mathrm{B} \partial$, and retain p50/RelA heterodimers in the cytoplasm. ${ }^{16,24}$ When p100 dimers form, one set of ankyrin repeats are free to bind an RelA/p50 complex and following IKK1 phosphorylation of a p100 subunit and regulated processing, this allows release of RelA/p50 in a similar manner to canonical I $\kappa \mathrm{B}$-dependent signalling. It is not clear yet whether this processing also occurs co-translationally and whether, for example, only one $\mathrm{p} 100$ is processed allowing release of $\mathrm{p} 50 /$ RelA or whether both p100s are processed liberating p50/p50 homodimers simultaneously. A further caveat when considering this model is that p100 dimers have not been shown experimentally.

Another problem hindering a complete understanding of activation of NF- $\kappa \mathrm{B}$ is the complexity of the family; there are 15 potential NF- $\kappa$ B dimers that can form, with only 12 of these capable of binding DNA in their own right and 9 that have transcriptional activation domains. ${ }^{25}$ The canonical/noncanonical distinction does not adequately explain how, for example, p50 homodimers are regulated. p50 homodimers bind $I_{\kappa} \mathrm{B} \alpha$ far more weakly than Rel-containing dimers ${ }^{26}$ so $I_{\kappa} \mathrm{B} \alpha$ degradation may not contribute to p50 activation. Although p50 lacks transcriptional activation domains and could therefore function as a transcriptional repressor, it can bind activators such as $\mathrm{I} \kappa \mathrm{B} \zeta^{27}$ to activate transcription. This sort of complexity is obviously not dealt with by the simple canonical/non-canonical distinction. The potential for misunderstanding is compounded by the fact that frequently experimenters, including ourselves, look at degradation of $I_{\kappa} \mathrm{B}$, or p100 and observe generic activation of NF- $\kappa \mathrm{B}$ but do not unambiguously define which subunits are involved. Despite the inadequacy of the current nomenclature to describe activation of NF- $\kappa \mathrm{B}$ we feel compelled to use it to describe NF- $\kappa \mathrm{B}$ signalling because it is so widely used and there is insufficient space to expound an alternative. It is however worth bearing in mind its limitations. In the future, as pathways become better understood, it may make more sense to describe events slightly upstream in terms of the molecules required for and unique to a particular pathway. Such pathways may therefore more accurately be described in terms of key activating molecules, NF- $\kappa-\mathrm{B}$ essential modulator (NEMO) and kinases receptor-interacting serine/ threonine-protein kinase 1 (RIPK1) and NIK, and the picture that is emerging from recent reports is that TRAFs and IAPS are key regulators of the abundance or function of these molecules.

\section{TNFRSF-mediated activation of the RIPK1/NEMO pathway}

Activation of the canonical pathway is best characterized for TNF-R1. Until recently it was believed that following TNF binding to TNF-R1 the kinase RIPK1 is recruited and its K63 ubiquitylation serves as platform to assemble IKKs and TAK1. ${ }^{28,29}$ IKK1 and IKK2 are recruited through NEMO, ${ }^{28,29}$ a molecule that can bind to K63-linked ubiquitin chains but has a much higher affinity for linear ubiquitin chains. ${ }^{30}$ TAK1 is required to phosphorylate and activate IKK2 ${ }^{31}$ and IKK2 phosphorylates $\mathrm{I} \kappa \mathrm{B}$, which results in its ubiquitylation and degradation, thereby liberating RelA-containing dimers. clAPs and TRAF2 are RIPK1 ubiquitin ligases and although 
the details of TNF-R1 signalling will be discussed by Dixit and Wertz, a short summary of the key facts is provided here. TRAF2 has been reported to promote $\mathrm{K} 63$ ubiquitin ligation of RIPK1, 6,32 however deletion of the E2, UBC13, which functions with TRAF2 and TRAF6 to generate K63 chains, does not substantially affect TNF-induced NF- $\kappa$ B in MEFs. ${ }^{33}$ $\mathrm{A} 20$, an $\mathrm{NF}-\kappa \mathrm{B}$ inducible protein, is then believed to remove K63-linked ubiquitin chains and replace them with K48 ubiquitin chains resulting in the proteasomal degradation of RIPK1. ${ }^{6}$

The fact that UBC13 knockouts appear to respond to TNF relatively normally suggests that K63 E3 ligase activity of TRAF2 may not be required for RIP modification. In addition, several recent reports suggest that clAPs are required for ubiquitylation of RIPK1, because in their absence there is a total loss of RIPK1 ubiquitylation and an obvious increase in the levels of RIPK1 in the TNF-R1 signalling complex. ${ }^{10,11,34,35}$ The increase in RIPK1 levels at the TNF-R1 in clAP-deficient cells suggests that a proportion of the modified RIPK1 at the TNF-R1 is K48 ubiquitylated, in a cIAPdependent manner, and destined for degradation in the proteasome. This proposal fits with an earlier report showing that RIPK1 can be directly $\mathrm{K} 48$ ubiquitylated by $\mathrm{CIAP} 1^{7}$ and is consistent with results obtained with $\mathrm{K} 63$ or K48 specific antibodies which show strong K48 modification of RIPK1 within 10 min of TNF addition. ${ }^{36}$ Furthermore, because RIPK1 ubiquitylation is lost in TRAF2/TRAF5 double knockout MEFs, it suggests that the function of TRAF2 is to recruit clAPs to RIPK1. Consistent with this idea, a TRAF2 mutant that is no longer able to bind cIAPs cannot promote RIP ubiquitylation following TNF/TNF-R1 signalling (James Vince and John Silke, unpublished data). However it will be important to test different knockout cells with these new antibodies to see the effects on RIPK1 ubiquitylation.

clAP1 has been shown to be able to directly ubiquitylate NEMO in a non-K48-linked manner, which is intriguing, but further work is required before the physiological relevance of this finding is understood. ${ }^{37}$

Several other TNFSF receptors, such as FN14, promote $I \kappa \mathrm{B} \alpha$ degradation and canonical NF- $\kappa \mathrm{B}$ activation. ${ }^{12,17,38}$ It is possible that RIPK1 will be required to activate canonical $\mathrm{NF}-\kappa \mathrm{B}$ from these receptors, as it is for TNF-R1, although there are no studies that address this question. It is however also possible that other molecules within the receptor complex are ubiquitylated to provide an IKK2-activating platform.

\section{TNFRSF-mediated activation of the NIK pathway}

Many members of the TNFRSF are also capable of activating the non-canonical or alternative NF- $\kappa$ B pathway, for example, BAFF-R, CD40 and LT $\beta$ R. TRAF2 and TRAF3 bind to sequences in TNFSF receptors containing sequences that match $(P S A T) \times(Q E) E$ and $P x Q x x D,{ }^{39}$ but the binding site extends beyond these motifs and TRAF binding to TNFRSF receptors, or other proteins, is not restricted to these sequences. Thus TRAF3 binds a PVPAT motif in BAFFR ${ }^{40}$ and TRAF2 binds TRADD, which does not contain such a consensus, with a higher affinity than it does to TNFRSF members that do contain the sequence. ${ }^{41}$ TNFRSF members may have cytoplasmic binding sites for either TRAF2/5 (e.g.,
Fn14, CD40 ${ }^{42}$ ), TRAF3 (e.g., CD40, ${ }^{43}$ BAFF-R ${ }^{44}$ ), TRAF6 (e.g., CD40 ${ }^{42}$ ) or several different binding sites (e.g., CD40 ${ }^{18}$ ). Some of the first studies with TRAFs demonstrated that their over-expression was sufficient to activate $\mathrm{NF}-\kappa \mathrm{B}$, so it was puzzling that receptor activation of NF- $\kappa$ B was associated with receptor-mediated TRAF degradation. For example, CD30 was reported to promote the degradation of TRAF2 in a nonproteasomal-dependent manner, ${ }^{45,46}$ TNF-R2 induces the proteasomal degradation of TRAF2 ${ }^{47}$ and both TRAF3 and TRAF2 are degraded by ligand-activated CD40. ${ }^{48,49}$ Although it was difficult at the time to see how diametrically opposite effects on TRAF levels could result in the same outcome, we now understand how TRAF degradation is required for activation of $\mathrm{NF}-\kappa \mathrm{B}$ and the link with the key non-canonical kinase NIK.

NIK was originally identified on the basis of its ability to bind TRAF2 and believed to thereby involve in activation of canonical NF- $\kappa \mathrm{B}^{50}$ However TRAF3 was subsequently shown to interact directly with NIK and mediate its constitutive polyubiquitylation and proteasome-dependent degradation. ${ }^{49}$ TRAF3 over-expression was shown to inhibit nuclear translocation of $\mathrm{p} 52$ induced by over-expression of multiple TNFRSF members including RANK, CD30 and CD40, ${ }^{42}$ suggesting that TRAF3 was an inhibitor of the activation of non-canonical NF- $\kappa \mathrm{B}$ and that loss of TRAF3 induced by TNFSF signalling could allow the accumulation of NIK and increased processing of p100 NF- $\kappa$ B2.

Constitutive and ubiquitous ablation of TRAF3 gene expression in mice results in perinatal death. Consistent with the idea that TRAF3 is involved in inhibiting non-canonical activation of $\mathrm{NF}-\kappa \mathrm{B}$, the lethal phenotype of $\mathrm{Traf3}^{-/}$mice can be rescued by eliminating expression of either $\mathrm{NIK}^{51}$ or NF- $\kappa$ B2. ${ }^{52}$ In addition to demonstrating that TRAF3 can regulate NIK in vivo, this data also shows that global activation of the alternative NF- $\kappa$ B pathway can be lethal. It is worth noting however that specific deletion of the ankyrin repeats of p100 caused elevated levels of nuclear NF- $\kappa$ B but resulted in gastric hyperplasia and a more delayed post-natal lethal phenotype than observed in the TRAF3 knockouts. ${ }^{53}$ Further data supporting the concept that TRAF3 is required to inhibit non-canonical NF- $\kappa$ B came from studies where TRAF3 was re-introduced intro TRAF3 knockout cells which showed that the RING of TRAF3 was required for TRAF3 to prevent increase in NIK levels and p100 processing. Cells derived from $\mathrm{Traf3}^{-1-}$ mice also exhibit increased levels of nuclear RelA $A^{51}$ consistent with the proposal that p100 functions as a fourth $I_{\kappa} \mathrm{B}$ molecule ${ }^{24}$ but also with the idea that TRAF3 regulates the canonical NF- $\kappa \mathrm{B}$ pathway in a p100-independent manner. ${ }^{54}$

As with Traf3 $^{-1-}$ mice, Traf2 ${ }^{-1-}$ mice die soon after birth. ${ }^{55}$ In this case the lethal phenotype was suspected to be due to increased sensitivity to TNF, because TRAF2-deficient cells were hypersensitive to TNF cytotoxicity and this suspicion was confirmed when it was shown that the lethality associated with TRAF2 deficiency could be avoided if the animal also lacked expression of TNF or TNF-R1. ${ }^{56}$ Because NF- $\kappa$ B is required to protect cells from TNF cytotoxicity and TRAF2 expression activates $\mathrm{NF}-\kappa \mathrm{B}$, it was expected that TRAF2 knockouts would have defects in activation of $\mathrm{NF}-\kappa \mathrm{B}$ in response to TNF, however surprisingly NF- $\kappa$ B was apparently 
activated normally in response to TNF ${ }^{55,57}$ Experiments with TRAF2 conditional knockout mice helped resolve this conundrum, because, far from having normal NF- $\kappa$ B activation, TRAF2-deficient $B$ cells had highly elevated TRAF3 levels and p100 processing. ${ }^{58}$ Further work showed that Traf2 $^{-1-}$ MEFs also had elevated levels of NIK and increased p100 processing. ${ }^{11}$ In this context, and given the results with the TRAF3 knockout animals, it is therefore not surprising, in retrospect, that the lethal phenotype of $\mathrm{Traf2}^{-1-}$ mice was also reversed by the loss of one copy of the NIK gene. ${ }^{51}$ Because increased levels of NIK are unlikely to increase sensitivity to cytotoxic TNF-R1 signalling, ${ }^{54,59}$ this suggests that the NIKdependent activation of the alternative NF- $\kappa$ B pathway that occurs upon depletion of TRAF2 ${ }^{58}$ also contributes to the lethal phenotype of Traf2 $^{-/}$mice.

A further piece in the puzzle came with the realization that TRAF2 works in concert with clAPs to keep NIK levels low in unstimulated cells. The development of IAP antagonist compounds that bind in the BIR2 and 3 grooves of IAPs and cause the specific degradation of clAPs greatly accelerated our understanding of the role IAPs have in this pathway. These IAP antagonist compounds are remarkable because they rapidly activate the E3 ligase activity of the clAPs, which results in their total proteasomal destruction within minutes of being added onto cells (see also accompanying review by Mace et al.). Levels of IAP partners, such as TRAF2, do not seem to be affected by this antagonist-mediated destruction, thereby allowing several groups to use this class of compound to show that ablation of clAPs resulted in elevated NIK levels and p100 processing. ${ }^{11,51,60,61}$ Furthermore, clAP1 and TRAF2 knockout cells showed elevated NIK levels and p100 processing and this could not be further increased by addition of IAP antagonist compound, suggesting that TRAF2 and clAPs functioned in the same pathway. ${ }^{11}$ clAP1 and 2 were also able to promote the ubiquitylation and degradation of NIK when over-expressed in cells, but a clAP1 mutant that was unable to bind TRAF2 was unable to promote NIK degradation. ${ }^{60}$

The final pieces of the puzzle were snapped into place when it was shown that NIK/TRAF3/TRAF2/clAPs were part of the same complex that was required to maintain low levels of NIK in unstimulated cells ${ }^{51,61}$ and that recruitment of TRAFs and or clAPs to various TNFSF receptors resulted in their degradation and allowed NIK levels to rise (Figure 1; Refs $\left.^{11,51,60}\right)$. In this NIK-regulating complex, TRAF2, TRAF3 and clAPs perform non-redundant functions. TRAF3 interacts with TRAF2, and NIK and clAPs are the K48 E3 ligases for NIK and are recruited to NIK through the TRAF2/TRAF3 interaction (Figure 1; Varfolomeev et al. ${ }^{60}$ ). This model neatly explains why loss of any component is sufficient to cause a rise in NIK levels and increased processing of p100. This model also explains why multiple myeloma cells that have high levels of NF- $\kappa \mathrm{B}$ activity, that is required for their survival, frequently carry genetic mutations that cause the inactivation of TRAF2, TRAF3, clAP1/clAP2 or the activation of $\mathrm{NF}_{\kappa} \mathrm{B} 1$, $\mathrm{NF} \kappa \mathrm{B} 2$ or NIK. ${ }^{62,63}$

This model also explains how stabilization of NIK can be achieved by diverse receptors such as Fn14 and BAFF-R that use different molecular strategies to achieve the same final outcome. For example, TWEAK/FN14 triggers CIAP and TRAF2 lysosomal degradation ${ }^{12}$ whereas receptors like BAFF-R promote proteasomal degradation of TRAF3. Similarly, CD40 has been shown to promote TRAF2-dependent TRAF3 degradation. ${ }^{64}$ CD30 can promote TRAF2 and clAP1 a

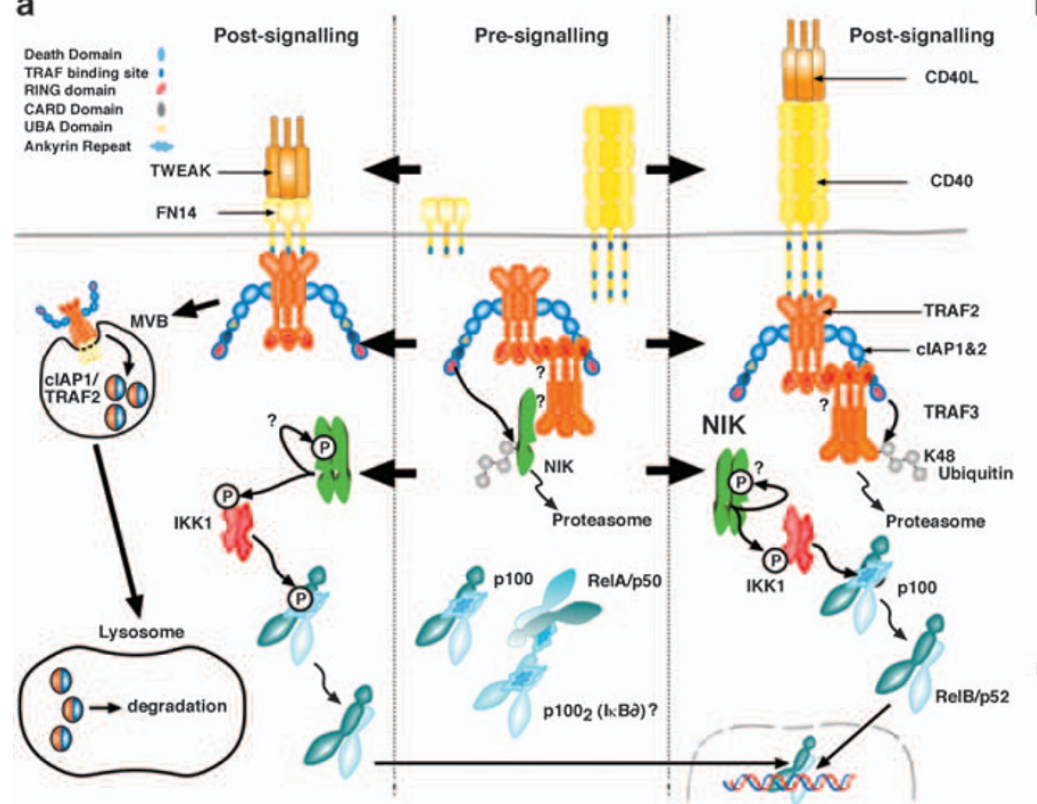

b

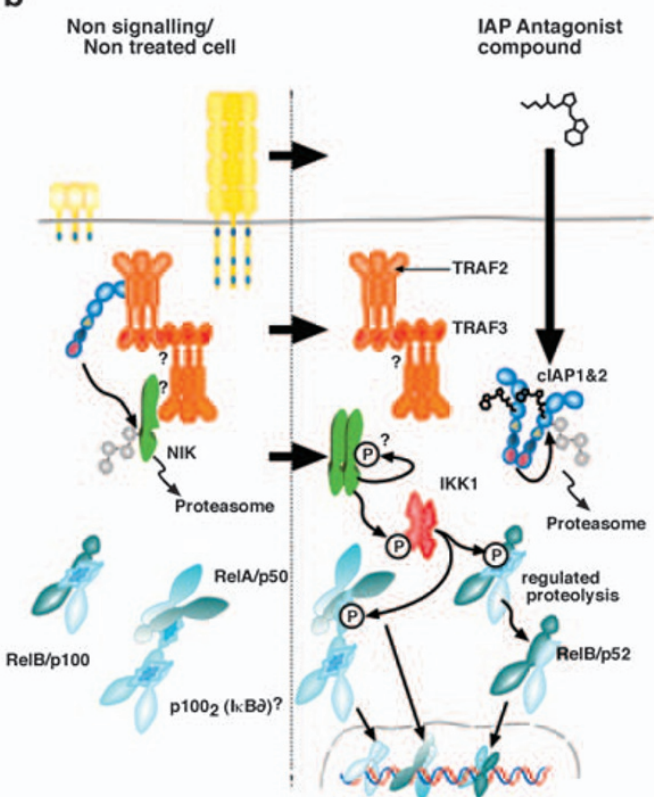

Figure 1 (a) A schematic showing how different TNFRSF signalling paradigms result in elevation of NIK levels and phosphorylation and processing of p100. Processing of

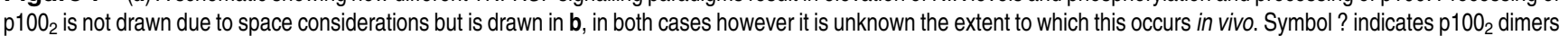
not proven to exist in vivo. (b) A schematic showing how IAP antagonists promote degradation of cIAPs and result in elevation of NIK levels and phosphorylation and processing of $p 100$. Potential NF- $\kappa$ B hetero- and homodimers that could be activated by $p 100$ processing are indicated. Symbol ? indicates predicted but molecular interaction unproven 


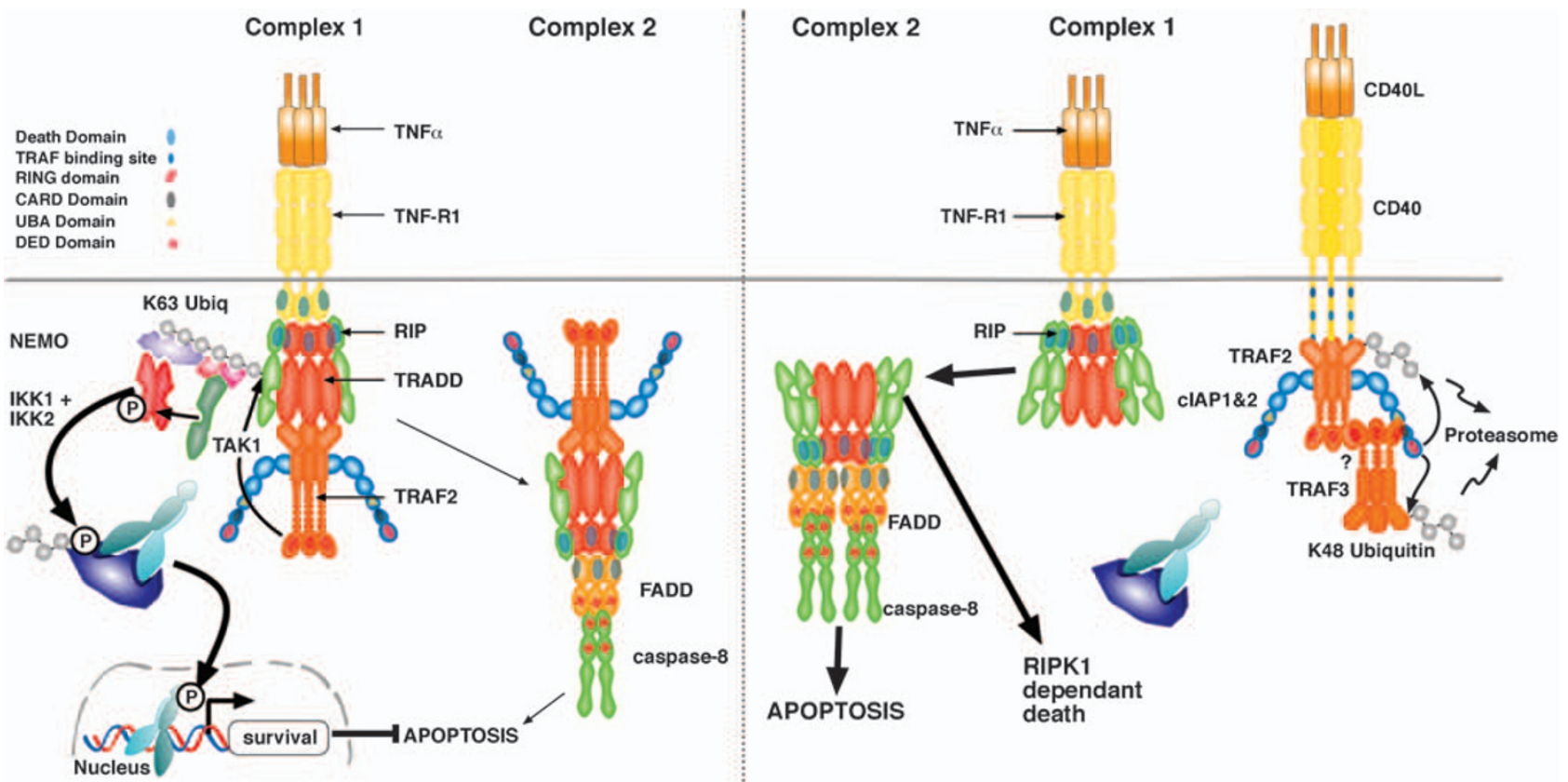

Figure 2 A schematic indicating normal TNF signalling (left) and how loss of cIAPs and TRAFs induced by non-DD containing TNFRSF signalling can sensitize cells to the cytotoxic effects of TNF (right). Similar mechanisms probably take place when cells are treated with synthetic IAP antagonist compounds that induce degradation of clAPs

degradation $^{46}$ that may be non-proteasomal ${ }^{45}$ although in these experiments TRAF2 degradation was induced by expression of a chimeric CD28-CD30 vector that may not mimic the physiological signal. Despite the fact that these different ligands induce different downstream effects on clAPs and TRAFs, all are able to cause an elevation in NIK levels and the subsequent processing of $\mathrm{p} 100$. As mentioned earlier, some TNFRSF members, such as FN14, are also able to cause $\mid \kappa \mathrm{B} \alpha$ degradation and it is an interesting question whether the different ways of activating TRAFs and clAPs that these receptors use can allow simultaneous activation of the canonical pathway. Furthermore, as discussed below, these different strategies also have the potential to integrate with signalling from other TNF receptors such as TNF-R1 itself (Figure 2).

\section{JNK and ASK signalling}

Loss of TRAF2 prevents activation of the JNK pathway in response to TNF signalling, ${ }^{55}$ and signalling from other TNFSF receptors such as CD40 has been shown to activate JNK. $^{65}$ Likewise, loss of clAPs results in activation of JNK signalling. ${ }^{66}$ In Drosophila, the insect IAP antagonist Reaper was shown to inhibit DIAP1 and activate JNK signalling by antagonizing DIAP1's regulation of DTRAF1 levels. Because Reaper-induced cell death in the fly eye could be suppressed by DTRAF1 mutant, then at least in this system JNK activity is pro-apoptotic. ${ }^{67}$ Apart from glimpses such as these however, our understanding of JNK pathways in TNFRSF signalling is only rudimentary and should prove an interesting area for further investigation.

Another finding supporting the idea that CIAPs and TRAF2 regulate kinase levels downstream of TNFSF receptors comes from the Ashwell lab. These authors showed that
TNF-R2 signalling specifically caused ASK1 ubiquitylation and proteasomal degradation. The specificity is surprising because in 4E3 cells, at least, NIK levels were not affected by TNF-R2 signalling. In these cells however, NIK was already easily detectable in unstimulated cells perhaps preventing a further increase following TNF-R2-induced TRAF2 and clAP1 degradation through the mechanism discussed above. In primary B cells from clAP1 knockout animals both TRAF2 degradation and ASK1 degradation were prevented in response to TNF-R2 signalling. ${ }^{66} \mathrm{JNK}$ phosphorylation in response to TNF-R2 signalling was also prolonged in clAP1-/- B cells. Because ASK1 knockout MEFs did not show such prolonged JNK activation as wildtype MEFs, it is possible that the failure to degrade ASK1 in clAP1 knockout B cells causes this increased JNK phosphorylation but data showing a physiological consequence of this increased JNK signalling are not available.

\section{Different signalling from the same receptors}

Another question that needs to be resolved is how the form of the TNFSF ligand affects the signalling from the receptor. TNFSF ligands are type II membrane proteins that naturally form trimers. In most ligands, the intermediate region separating the receptor binding and the transmembrane regions can be proteolytically cleaved to release a soluble (s) form of the ligand. Proteolytic cleavage is mediated either by metalloproteases (e.g., TNF and FasL) or by members of the furin proprotein convertase family of serine proteases (e.g., BAFF and TWEAK). The activities of the soluble and membrane-bound forms of the ligands have been compared side by side and shown to be quite different. For example, sTNF, generated by the metalloprotease TACE, is an activator of TNF-R1 signalling whereas only the membrane- 
bound form is able to activate both TNF-R1 and R2, ${ }^{68}$ and membrane-bound FasL is a potent killer whereas sFasL is not. ${ }^{69,70}$

Experimentally, researchers have tried different strategies to mimic the membrane-bound form. The strategy that most closely mimics the physiological situation is where cells expressing the membrane-bound form of the ligand are coincubated with the receptor cells (e.g., Neuro2A-FasL ${ }^{69}$ ) however this is not always practical. Another approach is to use a recombinant ligand fused to a naturally dimeric partner such as the Fc portion of an $\operatorname{lgG},{ }^{70}$ which generates a dimer of the natural trimer or hexameric ligand, or other multimeric proteins such as ACRP. It has been shown that the hexameric ligand is sufficient to reproduce the effects of the membranebound form of the ligand, at least for specific examples of cell killing and cell growth tested with FasL and CD40. ${ }^{70} \mathrm{~A}$ similar approach to the Fc fusion approach is to cross-link a trimeric ligand with antibody. This method can generate highly multimeric ligand that may approximate the membrane-bound ligand. It may not always be a physiological mimic, however, because membrane-bound CD40L was able to activate IL8 production whereas antibody cross-linked CD40 could not, ${ }^{71}$ Fc CD40L was also noted to produce greater responses when further cross-linked. ${ }^{70}$ It is possible therefore that the soluble form of the ligand has different downstream effects on TRAF and clAP recruitment and or degradation and it will be interesting to test this hypothesis.

\section{Secondary signalling complexes}

Another, potentially related question is the role of intracellular translocation in the signalling process and the role IAPs and TRAFs have in this process. Most of the data for a role of translocation in signalling relate specifically to TNF-R1, which is technically beyond the scope of this review, however we discuss some of the issues that TNF-R1 signalling has thrown up, as it is plausible that themes will apply to non-DDcontaining receptors. One of the key findings that advanced our understanding of how TNF-R1 signals was the realization that there are two complexes generated; a plasma membrane-bound complex that activates NF- $\kappa$ B and a secondary cytoplasmic complex that contains caspase- 8 and the apoptotic activity. ${ }^{72}$ A similar, although different finding was made around the same time showing that TNF-R1 internalization through endocytic vesicles, coined receptosomes, was required for aggregation of TRADD, FADD and caspase8 to TNF-R1. Others have shown that the translocation of TRAF2 to a detergent-insoluble compartment occurred in a TRAF2 RING-dependent manner and was required for JNK but not NF- $\kappa \mathrm{B}$ activation in response to TNF. ${ }^{73}$ This translocation was prevented when Ubc13 was knocked down, but in a separate study, UBC13 knockout cells displayed normal NF- $\kappa$ B and JNK activation in response to TNF. ${ }^{33}$ Similar findings about translocation were made following TNF-R2 signalling, but in this case TRAF2 translocated to a detergent-insoluble compartment that by confocal microscopy was judged to colocalize with the $E R^{74}$ and this occurred in a Ubc6-dependent manner.

The idea that the molecular features of TNF-R1 signalling might be a general strategy used by the family is supported by recent data that show that activation of MEKK1 and MAPK cascades in response to CD40 signalling occurs in a two-step process. ${ }^{75}$ The kinases are recruited to the membrane-bound complex in a TRAF2-dependent manner. Because Ubc13 was also required for kinase recruitment, this suggests that E3 ligase activity of TRAF2 was required for recruitment. MEKK1 recruited into the membrane complex is however inactive; activation appears to depend on release of the complex from the receptor into the cytosol. clAPs are required for formation of the cytosolic complex and in their absence TRAF3 does not become ubiquitylated and degraded. These data suggest a satisfyingly simple model whereby clAP K48 ubiquitylates TRAF3 and the proteasomal degradation of TRAF3 allows the release of membrane-bound complex into the cytosol. ${ }^{75}$

Internalization of many different receptor classes following ligand binding depends on ubiquitin signals ${ }^{76}$ and it will not therefore be too surprising if clAPs or TRAFs regulate a receptor-mediated internalization event. It will however be interesting to learn more about the nature of these secondary signalling complexes and whether, for example, signalling complexes assembled on endocytic vesicles or cytosolic complexes result in different downstream outcomes.

\section{Translocation or degradation?}

TNFRSF signalling frequently causes the degradation of either TRAFs, clAPs or both but one outstanding question is whether translocation is sufficient to allow elevation in NIK levels and whether translocation without degradation is a biological outcome from these receptors. This seems a possibility because BAFF stimulation of $B$ cells in vitro was sufficient to activate alternative $\mathrm{NF}-\kappa \mathrm{B}$ without any detectable TRAF3 degradation. ${ }^{58}$ Similarly, inhibiting TWEAK-induced degradation of TRAF2 with a cathepsin B inhibitor was not able to block elevation in NIK levels and processing of $\mathrm{p} 100$ whereas disruption of lysosomes with $\mathrm{NH}_{4} \mathrm{Cl}$ was. ${ }^{12}$ From a cellular perspective, a TRAF2/cIAP1 complex enclosed within a lysosome or other membrane-bound compartment is probably indistinguishable from a degraded TRAF2/cIAP1 complex.

\section{Other consequences of cIAP/TRAF depletion}

One observation made early in the history of TNFRSF signalling was that signalling from certain TNFSF members without DDs could nevertheless kill cells. ${ }^{77}$ This killing activity was shown to be due to autocrine production of TNF $\alpha$, but as TNF does not normally kill cells it was also realized that signalling by these TNFSF members had to have an additional function in sensitizing cells to TNF. ${ }^{78}$ One possible clue to what that function could be came from the observation that the sensitivity to TNF induced by TNFSF signalling correlated with a loss of TRAF2 ${ }^{47,79}$ that may be caused by clAP1 E3 ligase activity. ${ }^{47}$ These studies have a particular resonance with IAP antagonist studies discussed earlier because IAP antagonists killed certain types of cells in the same manner; by inducing TNF production and simultaneously sensitizing cells to TNF. The fact that the same cells that were sensitive to TNFSFmediated autocrine TNF production were sensitive to IAP antagonists ${ }^{11,12,80}$ supports the idea that loss of clAPs and 
TRAF2 induced by TNFSF signalling is sufficient to sensitize cells to TNF (Figure 2).

Because different TNFRs recruit distinct sets of TRAFs and IAPs and promote different degrees of reduction in TRAF2/ clAP levels, signalling from different TNFRSF members will synergize differently with TNF. For example, TNF-R2 signalling or TWEAK signalling that reduces levels of TRAF2 and ClAPs should sensitize cells to the cytotoxic activity of TNF ${ }^{12}$ whereas BAFF-R signalling that only promotes TRAF3 degradation would not be expected to sensitize cells to TNF. TNF ligands are frequently present in the same physiological situations, for example, TNF and TWEAK in wounds ${ }^{81}$ so it is feasible that such cross talk occurs. The timing of signalling does however need to be taken into consideration; TWEAKinduced degradation is not rapid and therefore if it is administered at the same time as TNF it would not affect the initial wave of NF- $\kappa \mathrm{B}$ and in fact can augment $I_{\kappa} \mathrm{B} \alpha$ degradation. ${ }^{12}$ Furthermore, TWEAK signalling could alter the apoptotic potential of a cell by upregulating anti-apoptotic molecules and again the timing of signalling would be of critical importance. It is therefore not a trivial matter to predict how signalling intersects in vivo, in either chronic or acute situations, but it is clear that the potential exists.

Physiological Relevance of TRAF2/TRAF3/cIAP Function: B-Cell Survival. Mature primary B lymphocytes (B cells) are unique within the body because they are completely dependent for their in vivo survival on BAFF signals delivered through its receptor BAFF-R. ${ }^{82-84}$ The crucial role that CD40L-mediated triggering of CD40 has in immune responsiveness of $B$ cells and the role of TRAFs in this pathway are covered in detail in recent reviews by Bishop and co-workers ${ }^{17,38}$ and will not be discussed here.

Activation of the alternative NF- $\kappa$ B pathway is a key survival signal for $B$ cells reflected by the greatly reduced $B$-cell numbers in both p100- and NIK-deficient mice. ${ }^{85,86} \mathrm{~B}$ cells therefore represent an excellent model to test the applicability of in vitro signalling data to an in vivo physiological setting. Because of the lethal phenotype of $\mathrm{Traf2}^{-1}$ and $\mathrm{Traf3}^{-1-}$ mice, rigorous examination of the impact on primary $B$ cells of absent TRAF2 or TRAF3 expression requires conditional inactivation within the B-lineage using 'floxed' Traf2 or Traf3 alleles in combination with Cre expression from the CD19 promoter. This approach yielded the first indication that TRAF2 acts as a negative regulator of the alternative NF- $\kappa$ B pathway, as the TRAF2-deficient $B$ cells in these mice exhibited increased p100 processing and nuclear p52. ${ }^{58}$ Consistent with the elevated activation of this key B-cell survival pathway, TRAF2-deficient B cells exhibited extended survival and accumulated in large numbers in vivo. ${ }^{58}$ Mice with B-cell-specific TRAF3 deficiency ${ }^{87,88}$ or indeed absent expression of both TRAF2 and TRAF3 ${ }^{87}$ were subsequently found to have a virtually identical phenotype, consistent with the co-operative but non-redundant actions of TRAF2 and TRAF3 in suppressing the alternative NF- $\kappa$ B pathway.

A particularly significant finding using this in vivo approach is that B-cell-specific absence of either TRAF2 ${ }^{87}$ or TRAF3 (unpublished observations) allows B cells to develop and survive in vivo in the complete absence of BAFF. This demonstrates that TRAF2 and TRAF3 do not simply dampen the survival signals triggered through BAFF-R, but that the primary function of BAFF-R signalling is to reverse the constitutive repression of $\mathrm{B}$-cell survival by these molecules. As described above, this is achieved by the induction of TRAF3 degradation, a process that depends on the presence of TRAF2. ${ }^{87}$ In the light of the recent information on the function of ClAP1/2 in mediating TRAF2-dependent degradation of NIK, it is possible that $B$ cells lacking expression of clAP1/2 would also exhibit constitutive activation of B-cell survival pathways. A hint that this may be the case comes from experiments in which in vitro B-cell survival was extended by the treatment with IAP antagonist. ${ }^{61}$ This possibility, plus the possibility that the clAPs are required for BAFF-induced TRAF3 degradation, awaits targeted deletion of clAP1/2 in $\mathrm{B}$ cells. If the clAPs are required for these functions, they will almost certainly perform these functions redundantly because both $c l a p 1^{-/-}$and $c l a p 2^{-/-}$mice exhibit apparently normal B-cell compartments.

\section{Other E3 ligases}

Although this review has focused on the ubiquitin E3 ligase role of TRAFs and IAPs in regulating TNFRSF signalling, there is recent evidence to suggest that ubiquitin regulation of TNF-R1 is far more complex than this. This further underlines the importance of one of our initial questions; why is there such an abundance of E3 ligases regulating this pathway and what might their specific roles be? Recent papers have shown that several different RING containing E3 ligases, such CARPs,${ }^{89,90} \mathrm{RNF} 11^{91}$ and $\mathrm{HOIL}-1^{92}$ may be involved in regulating TNF-R1 signalling. HOIL-1 is particularly fascinating because this E3 ligase can perform linear ubiquitylation of substrates. ${ }^{93}$ Structurally, linear ubiquitin chains mimic K63 ubiquitin chains and are a better NEMO binding structure than K63-linked ubiquitin chains. ${ }^{30}$ These new players will be watched with interest to see whether they interact with or modify the activity of TRAFs and IAPs in regulating other TNFSF signalling pathways.

\section{TRAFs and IAPs in innate immune signalling}

Drosophila lacks an adaptive immune system and therefore relies on innate immune responses. The Imd (immune deficiency) pathway allows Drosophila to detect and respond to Gram-negative bacteria and induces expression of antibacterial peptides in an NF- $\kappa$ B-family-dependent manner. ${ }^{94}$ The Imd pathway shares a clear similarity with the mammalian TNF-R1 signalling pathway; the activated receptor PGRP recruits Imd, which shares homology with the DD of RIPK1, which in turn recruits dFADD, dTAK1, dTAB2 and the Drosophila IKK complex; IKK $\beta$ and IKK $\gamma /$ Kenny are all required to activate the NF- $\kappa B$ transcription factor Relish which is similar to the mammalian p105 NF- $\kappa$ B1 molecule. $\kappa \mathrm{B}$ binding sites within the promoters of anti-bacterial peptides then drive transcription from these promoters. There are several differences to the TNF-R1 pathway; although Imd has an RIP-like DD, it does not have an RIP-like kinase domain and in the Imd pathway Relish processing is effected by a caspase whereas TNF-induced activation of NF- $\kappa \mathrm{B}$ appears to be caspase independent (Figure 3a). 

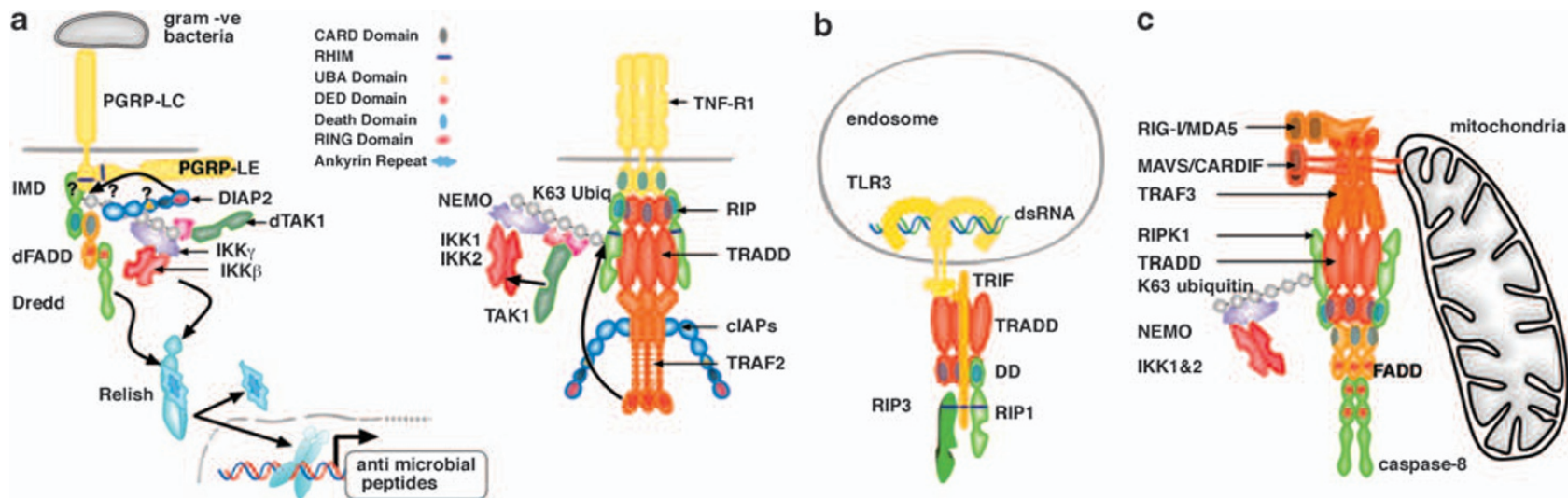

Figure 3 A schematic indicating the shared molecular components between innate immune signalling complexes and TNFR signalling complexes. (a) Drosophila Imd pathway with complex 1 of TNF-R1 shown for comparison. (b) Mammalian TLR3 pathway. RIPK1 is ubiquitylated in response to TLR3 ligands, ${ }^{1}$ which may lead to the recruitment of TAK1 in an analogous manner to the TNF -R1 pathway but this has not been demonstrated. (c) Mammalian RIG-I/MAVS pathway. RHIM, RIP homotypic interaction motif; ?, predicted but molecular interaction unproven. The bacteria, endosome and mitochondria are not drawn to scale

Nevertheless, as in mammals, ubiquitylation regulates this pathway and Drosophila Ubc13 (Bendless/UEV1A), an E2 ubiquitin-protein-conjugate complex that facilitates K63-linked polyubiquitylation, is required to activate dTAK1 and the IKK complex. In addition, DIAP2 is required in vivo to protect Drosophila against Gram-negative bacterial infection ${ }^{95}$ and it will be interesting to find out whether, as in the TNF-R1 pathway, DIAP2 is required to ubiquitylate Imd or dTAK1. In the same study a role for dTRAF2 was excluded but it is possible that one of the other dTRAFs can substitute for dTRAF2 in the fly.

The similarities of this Drosophila innate immune response pathway with the mammalian TNF-R1 pathway are striking and suggest that DIAPs will regulate signalling in a similar manner to their mammalian homologues. This conservation also stimulates a further question; could IAPs and TRAFs be involved in regulating other innate immune pathways in mammals? There is clear evidence that TRAFs and RIP are critical in the formation and regulation of mammalian innate immune system complexes and very recent data show clAPs also have a role in regulating at least one of these pathways in the same manner that they regulate TNF-R1 and other TNFRSF signalling pathways ${ }^{96}$ (Figure $3 b$ and c). In the following section we provide short illustrative examples of two pathways where RIP and or TRAFs have important roles in the propagation of signalling from distinct innate immune cassettes that may be regulated in a similar manner to that already discussed for TNFRSF.

\section{cIAPs, RIP kinases and TRAFs in TLR and NOD signalling}

Both NF- $\kappa$ B and MAPK pathways are activated by Toll-like receptors (TLRs), transmembrane receptors that examine the extracellular environment, including extracellular compartments such as the endosome, for pathogen-associated patterns (PAMPs). TLR3 activates NF- $\kappa \mathrm{B}$ and MAPK in response to endosomal double-stranded RNA in an RIPK1dependent manner ${ }^{97,98}$ and RIPK1 is recruited together with TRADD, TRAF6, TAB1, TAB2 and TAK1, revealing the underlying symmetry of the activating cassette with the ancestral Drosophila pathway and with TNF-R1. TRADDdeficient cells have impaired NF- $\kappa$ B responses in response to the TLR3 agonist poly(dl/dC) in MEFs ${ }^{99,100}$ and TRAF6 knockouts fail to activate this pathway. ${ }^{4}$ Although cIAP1 and 2 are most likely recruited indirectly to RIP through TRAF2 in TNF-R1 signalling, CIAP1 and 2 have also been shown to interact directly with $\mathrm{RIPK} 1^{7}$ and therefore it is plausible that IAPs may regulate this pathway (Figure $3 b$ ).

Consistent with the hypothesis that CIAPs regulate RIP kinases and are important in innate immune signalling, Bertrand et al. ${ }^{96}$ recently reported that CIAP1 and CIAP2 regulate another innate immune signalling cassette, NOD1 and NOD2, by acting as E3 ligases for RIPK2. RIPK2 is a homologue of RIPK 1 but contains a CARD domain rather than a DD and does not have an RHIM domain. Although both clAPs and RIPK2 contain CARD domains, their interaction does not occur through the CARD domain, ${ }^{96}$ therefore the function of the CIAP CARD domain remains enigmatic. Like RIPK1, RIPK2 can become ubiquitylated with K63 ubiquitin chains that serve as a scaffold for TAK1 recruitment, and, as in TNF-R1 signalling, A20 has a key function in limiting NOD/ RIPK2 activation of NF- $\kappa$ B by deubiquitylating RIPK2. ${ }^{101}$ In addition to TLRs and NODs, other innate immune sensors exist to detect PAMPs in the cytoplasm such as the DAI (ZBP1/DLM-1) and MAVS/RIG-I pathways.

\section{RIP and TRAFs in DAI and MAVS/RIG-I signalling}

DAl is yet another innate regulator that activates NF- $\kappa$ B in an RIPK1-dependent manner. ${ }^{102}$ DAl is a cytosolic DNA sensor that activates IRF3 and NF- $k$ B pathways to promote type I interferon production. Like the TLR3 pathway, RIPK3 also appears to be involved. Given clAPs known ability to regulate RIPK1 it seems highly likely that clAPs will regulate this pathway but there are no data to support this hypothesis as yet.

In the MAVS (also called VISA, IPS-1 or Cardif)/RIG-I pathway, which is required to detect cytoplasmic viral RNAs and resist viral infection, TRADD is recruited to the CARDcontaining protein Cardif and forms a complex with TRAF3, FADD and RIPK1 and this complex is able to activate IRF3 
and NF- $\kappa \mathrm{B} .{ }^{103}$ In the absence of TRADD, cells produced less IFN $\beta$ in response to VSV and Sendai virus and viral replication was enhanced, but the effect of TRAF3 loss was not investigated. This study therefore raises many questions concerning how signalling is regulated by TRAF3 and whether clAPs could be involved. The enormous use of the clAP/ TRAF/TRADD/RIP signalling cassette by so many important immune receptors also begs the question how these pathways might intersect and how levels of these key players could affect signalling outcomes.

\section{The end of the beginning?}

When the clAPs were identified, bound indirectly to TNF-R2 through TRAF2, nothing was known about their function. For a long time, unlike the TRAFs with which they were associated, it also seemed that whatever their actual function, it would not be a particularly important one, because the individual knockouts had rather bland phenotypes. ${ }^{104,105}$ In this context, the $C I A P$ gene duplication seemed to be only a recent biological quirk. The development of IAP antagonist compounds, designed primarily to inhibit XIAP to sensitize tumour cells to chemotherapy, has however completely changed our understanding of the TRAF/cIAP partnership and shown how pivotal it is to the survival of cancer cells and in the function of the immune system. It seems now likely that the gene duplication of the clAPs is in fact a reflection of an extremely important function for these proteins in the mammalian immune system and it will be fascinating to see what happens in the compound knockouts.

Acknowledgements. We thank James Vince and Emmanuel Dejardin for critical reading of the paper and anonymous reviewers for their contributions. JS and RB were funded by the NHMRC grants (nos. 433013, 541901 and 541902) and (nos. 402724 and 427620), respectively. JS is a consultant for TetraLogic Pharmaceuticals.

1. Rothe M, Wong SC, Henzel WJ, Goeddel DV. A novel family of putative signal transducers associated with the cytoplasmic domain of the $75 \mathrm{kDa}$ tumor necrosis factor receptor. Cell 1994; 78: 681-692.

2. Naito A, Yoshida H, Nishioka E, Satoh M, Azuma S, Yamamoto T et al. TRAF6-deficient mice display hypohidrotic ectodermal dysplasia. Proc Natl Acad Sci USA 2002; 99: 87668771

3. Tsitsikov EN, Laouini D, Dunn IF, Sannikova TY, Davidson L, Alt FW et al. TRAF1 is a negative regulator of TNF signaling. Enhanced TNF signaling in TRAF1-deficient mice. Immunity 2001; 15: 647-657.

4. Wu H, Arron JR. TRAF6, a molecular bridge spanning adaptive immunity, innate immunity and osteoimmunology. Bioessays 2003; 25: 1096-1105.

5. Rothe M, Pan MG, Henzel WJ, Ayres TM, Goeddel DV. The TNF-R2-TRAF signaling complex contains two novel proteins related to baculoviral-inhibitor of apoptosis proteins. Cell 1995; 83: 1243-1252.

6. Wertz IE, O'Rourke KM, Zhou H, Eby M, Aravind L, Seshagiri S et al. De-ubiquitination and ubiquitin ligase domains of A20 downregulate NF-kappaB signalling. Nature 2004 430: 694-699.

7. Park SM, Yoon JB, Lee TH. Receptor interacting protein is ubiquitinated by cellular inhibitor of apoptosis proteins (c-IAP1 and c-IAP2) in vitro. FEBS Lett 2004; 566: 151156.

8. Christensen DE, Brzovic PS, Klevit RE. E2-BRCA1 RING interactions dictate synthesis of mono- or specific polyubiquitin chain linkages. Nat Struct Mol Biol 2007; 14: 941-948.

9. Blankenship JW, Varfolomeev E, Goncharov T, Fedorova AV, Kirkpatrick DS, IzraelTomasevic $\mathrm{A}$ et al. Ubiquitin binding modulates IAP antagonist-stimulated proteasomal degradation of C-IAP1 and C-IAP2(1). Biochem J 2009; 417: 149-160.

10. Bertrand MJ, Milutinovic S, Dickson KM, Ho WC, Boudreault A, Durkin J et al. clAP1 and cIAP2 facilitate cancer cell survival by functioning as E3 ligases that promote RIP1 ubiquitination. Mol Cell 2008; 30: 689-700.
11. Vince JE, Wong WW, Khan N, Feltham R, Chau D, Ahmed AU et al. IAP antagonists target ClAP1 to induce TNFalpha-dependent apoptosis. Cell 2007; 131: 682-693.

12. Vince JE, Chau D, Callus B, Wong WW, Hawkins CJ, Schneider P et al. TWEAK-FN14 signaling induces lysosomal degradation of a cIAP1-TRAF2 complex to sensitize tumor cells to TNFalpha. J Cell Biol 2008; 182: 171-184.

13. Vaux DL, Silke J. IAPs, RINGs and ubiquitylation. Nat Rev Mol Cell Biol 2005; 6: 287-297.

14. Varfolomeev E, Wayson SM, Dixit VM, Fairbrother WJ, Vucic D. The inhibitor of apoptosis protein fusion c-IAP2.MALT1 stimulates NF- $\kappa$ B activation independently of TRAF1 AND TRAF2. J Biol Chem 2006; 281: 29022-29029.

15. Wiley SR, Cassiano L, Lofton T, Davis-Smith T, Winkles JA, Lindner V et al. A novel TNF receptor family member binds TWEAK and is implicated in angiogenesis. Immunity 2001; 15: $837-846$

16. Basak S, Hoffmann A. Crosstalk via the NF-kappaB signaling system. Cytokine Growth Factor Rev 2008; 19: 187-197.

17. Xie P, Kraus ZJ, Stunz LL, Bishop GA. Roles of TRAF molecules in B lymphocyte function. Cytokine Growth Factor Rev 2008; 19: 199-207.

18. Schneider P. Signaling by TNF and related ligands. Oxford Monographs on Medical Genetics 2004; 49: 340-358.

19. Chen LF, Greene WC. Shaping the nuclear action of NF-kappaB. Nat Rev Mol Cell Biol 2004; 5: 392-401.

20. Mordmüller B, Krappmann D, Esen M, Wegener E, Scheidereit C. Lymphotoxin and lipopolysaccharide induce NF-kappaB-p52 generation by a co-translational mechanism. EMBO Rep 2003; 4: 82-87.

21. Coope HJ, Atkinson PG, Huhse B, Belich M, Janzen J, Holman MJ et al. CD40 regulates the processing of NF-kappaB2 p100 to p52. EMBO J 2002; 21: 5375-5385.

22. Claudio E, Brown K, Park S, Wang H, Siebenlist U. BAFF-induced NEMO-independent processing of NF-kappa B2 in maturing B cells. Nat Immunol 2002; 3: 958-965.

23. Dejardin E, Droin NM, Delhase M, Haas E, Cao Y, Makris $C$ et al. The lymphotoxin- $\beta$ receptor induces different patterns of gene expression via two NF- $\kappa$ B pathways. Immunity 2002; 17: 525-535.

24. Basak S, Kim H, Kearns JD, Tergaonkar V, O'Dea E, Werner SL et al. A fourth IkappaB protein within the NF-kappaB signaling module. Cell 2007; 128: 369-381.

25. Hoffmann A, Baltimore D. Circuitry of nuclear factor kappaB signaling. Immunol Rev 2006; 210: 171-186.

26. Phelps CB, Sengchanthalangsy LL, Huxford T, Ghosh G. Mechanism of I kappa B alpha binding to NF-kappa B dimers. J Biol Chem 2000; 275: 29840-29846.

27. Bates PW, Miyamoto S. Expanded nuclear roles for IkappaBs. Sci STKE 2004; 2004 pe48.

28. Wu CJ, Conze DB, Li T, Srinivasula SM, Ashwell JD. Sensing of Lys 63-linked polyubiquitination by NEMO is a key event in NF-kappaB activation [corrected]. Nat Cell Biol 2006; 8: 398-406.

29. Ea CK, Deng L, Xia ZP, Pineda G, Chen ZJ. Activation of IKK by TNFalpha requires sitespecific ubiquitination of RIP1 and polyubiquitin binding by NEMO. Mol Cell 2006; 22: 245-257.

30. Lo YC, Lin SC, Rospigliosi CC, Conze DB, Wu CJ, Ashwell JD et al. Structural basis for recognition of diubiquitins by NEMO. Mol Cell 2009; 33: 602-615.

31. Sato S, Sanjo H, Takeda K, Ninomiya-Tsuji J, Yamamoto M, Kawai T et al. Essential function for the kinase TAK1 in innate and adaptive immune responses. Nat Immunol 2005; 6: 1087-1095

32. Lee TH, Shank J, Cusson N, Kelliher MA. The kinase activity of Rip1 is not required for tumor necrosis factor-alpha-induced lkappaB kinase or p38 MAP kinase activation or for the ubiquitination of Rip1 by Traf2. J Biol Chem 2004; 279: 33185-33191.

33. Yamamoto M, Okamoto T, Takeda K, Sato S, Sanjo H, Uematsu S et al. Key function for the Ubc13 E2 ubiquitin-conjugating enzyme in immune receptor signaling. Nat Immunol 2006; 7: 962-970.

34. Mahoney DJ, Cheung HH, Mrad RL, Plenchette S, Simard C, Enwere E et al. Both clAP1 and cIAP2 regulate TNFalpha-mediated NF-kappaB activation. Proc Natl Acad Sci USA 2008; 105: 11778-11783.

35. Varfolomeev E, Goncharov T, Fedorova AV, Dynek JN, Zobel K, Deshayes K et al. c-IAP1 and C-IAP2 are critical mediators of tumor necrosis factor alpha (TNFalpha)-induced NFkappaB activation. J Biol Chem 2008; 283: 24295-24299.

36. Newton K, Matsumoto ML, Wertz IE, Kirkpatrick DS, Lill JR, Tan J et al. Ubiquitin chain editing revealed by polyubiquitin linkage-specific antibodies. Cell 2008; 134: 668-678.

37. Tang ED, Wang CY, Xiong Y, Guan KL. A role for NF-kappaB essential modifier/lkappaB kinase-gamma (NEMO/IKKgamma) ubiquitination in the activation of the IkappaB kinase complex by tumor necrosis factor-alpha. J Biol Chem 2003; 278: 37297-37305.

38. Bishop GA. The multifaceted roles of TRAFs in the regulation of B-cell function. Nat Rev Immunol 2004; 4: 775-786.

39. Ye H, Park YC, Kreishman M, Kieff E, Wu H. The structural basis for the recognition of diverse receptor sequences by TRAF2. Mol Cell 1999; 4: 321-330.

40. Ni CZ, Oganesyan G, Welsh K, Zhu X, Reed JC, Satterthwait AC et al. Key molecular contacts promote recognition of the BAFF receptor by TNF receptor-associated factor 3 : implications for intracellular signaling regulation. J Immunol 2004; 173: 7394-7400.

41. Park YC, Ye H, Hsia C, Segal D, Rich RL, Liou HC et al. A novel mechanism of TRAF signaling revealed by structural and functional analyses of the TRADD-TRAF2 interaction. Cell 2000; 101: 777-787. 
42. Hauer J, Püschner S, Ramakrishnan $\mathrm{P}$, Simon U, Bongers M, Federle $\mathrm{C}$ et al. TNF receptor (TNFR)-associated factor (TRAF) 3 serves as an inhibitor of TRAF2/5-mediated activation of the noncanonical NF-kappaB pathway by TRAF-binding TNFRs. Proc Natl Acad Sci USA 2005; 102: 2874-2879.

43. Hu HM, O'Rourke K, Boguski MS, Dixit VM. A novel RING finger protein interacts with the cytoplasmic domain of CD40. J Biol Chem 1994; 269: 30069-30072.

44. Xu LG, Shu HB. TNFR-associated factor-3 is associated with BAFF-R and negatively regulates BAFF-R-mediated NF-kappa $B$ activation and IL-10 production. $J$ Immunol 2002; 169: 6883-6889.

45. Duckett CS, Thompson CB. CD30-dependent degradation of TRAF2 - implications for negative regulation of TRAF signaling and the control of cell survival. Genes Dev 1997; 11: 2810-2821.

46. Csomos RA, Wright CW, Galbán S, Oetjen KA, Duckett CS. Two distinct signalling cascades target the NF-kappaB regulatory factor C-IAP1 for degradation. Biochem $J$ 2009; 420: 83-91.

47. Li X, Yang Y, Ashwell JD. TNF-RII and C-IAP1 mediate ubiquitination and degradation of TRAF2. Nature 2002; 416: 345-347.

48. Brown KD, Hostager BS, Bishop GA. Differential signaling and tumor necrosis factor receptor-associated factor (TRAF) degradation mediated by CD40 and the Epstein-Barr virus oncoprotein latent membrane protein 1 (LMP1). J Exp Med 2001; 193: 943-954.

49. Liao G, Zhang M, Harhaj EW, Sun SC. Regulation of the NF-kappaB-inducing kinase by tumor necrosis factor receptor-associated factor 3-induced degradation. J Biol Chem 2004; 279: 26243-26250.

50. Malinin NL, Boldin MP, Kovalenko AV, Wallach D. MAP3K-related kinase involved in NF-KB induction by TNF, CD 95 and IL-1. Nature 1997; 385: 540-544.

51. Vallabhapurapu S, Matsuzawa A, Zhang W, Tseng PH, Keats $\mathrm{JJ}$, Wang $\mathrm{H}$ et al. Nonredundant and complementary functions of TRAF2 and TRAF3 in a ubiquitination cascade that activates NIK-dependent alternative NF-kappaB signaling. Nat Immunol 2008; 9: 1364-1370.

52. He JQ, Zarnegar B, Oganesyan G, Saha SK, Yamazaki S, Doyle SE et al. Rescue of TRAF3-null mice by $100 \mathrm{NF}-\kappa \mathrm{B}$ deficiency. J Exp Med 2006; 203: 2413-2418.

53. Ishikawa H, Carrasco D, Claudio E, Ryseck RP, Bravo R. Gastric hyperplasia and increased proliferative responses of lymphocytes in mice lacking the $\mathrm{COOH}$-terminal ankyrin domain of NF-kappaB2. J Exp Med 1997; 186: 999-1014.

54. Zarnegar B, Yamazaki S, He JQ, Cheng G. Control of canonical NF-kappaB activation through the NIK-IKK complex pathway. Proc Natl Acad Sci USA 2008; 105 : 3503-3508.

55. Yeh WC, Shahinian A, Speiser D, Kraunus J, Billia F, Wakeham A et al. Early lethality, functional NF-kappaB activation, and increased sensitivity to TNF-induced cell death in TRAF2-deficient mice. Immunity 1997; 7: 715-725.

56. Nguyen LT, Duncan GS, Mirtsos C, Ng M, Speiser DE, Shahinian A et al. TRAF2 deficiency results in hyperactivity of certain TNFR1 signals and impairment of CD40mediated responses. Immunity 1999; 11: 379-389.

57. Lee SY, Reichlin A, Santana A, Sokol KA, Nussenzweig MC, Choi Y. Traf2 is essential for JNK but not NF-kappa-B activation and regulates lymphocyte proliferation and survival. Immunity 1997; 7: 703-713.

58. Grech AP, Amesbury M, Chan T, Gardam S, Basten A, Brink R. TRAF2 differentially regulates the canonical and noncanonical pathways of NF- $\kappa$ B activation in mature $B$ cells. Immunity 2004; 21: 629-642.

59. Ramakrishnan $P$, Wang $W$, Wallach $D$. Receptor-specific signaling for both the alternative and the canonical NF-kappaB activation pathways by NF-kappaB-inducing kinase. Immunity 2004; 21: 477-489.

60. Varfolomeev E, Blankenship JW, Wayson SM, Fedorova AV, Kayagaki N, Garg P et al. IAP antagonists induce autoubiquitination of c-IAPs, NF-kappaB activation, and TNFalpha-dependent apoptosis. Cell 2007; 131: 669-681.

61. Zarnegar BJ, Wang Y, Mahoney DJ, Dempsey PW, Cheung HH, He J et al. Noncanonical NF-kappaB activation requires coordinated assembly of a regulatory complex of the adaptors cIAP1, cIAP2, TRAF2 and TRAF3 and the kinase NIK. Nat Immunol 2008; 9 : 1371-1378.

62. Keats JJ, Fonseca R, Chesi M, Schop R, Baker A, Chng WJ et al. Promiscuous mutations activate the noncanonical NF-kappaB pathway in multiple myeloma. Cancer Cell 2007; 12: $131-144$

63. Annunziata CM, Davis RE, Demchenko Y, Bellamy W, Gabrea A, Zhan F et al. Frequent engagement of the classical and alternative NF-kappaB pathways by diverse genetic abnormalities in multiple myeloma. Cancer Cell 2007; 12: 115-130.

64. Hostager BS, Haxhinasto SA, Rowland SL, Bishop GA. Tumor necrosis factor receptorassociated factor 2 (TRAF2)-deficient $B$ lymphocytes reveal novel roles for TRAF2 in CD40 signaling. J Biol Chem 2003; 278: 45382-45390.

65. Pullen SS, Dang TT, Crute JJ, Kehry MR. CD40 signaling through tumor necrosis factor receptor-associated factors (TRAFs). Binding site specificity and activation of downstream pathways by distinct TRAFs. J Biol Chem 1999; 274: 14246-14254.

66. Zhao Y, Conze DB, Hanover JA, Ashwell JD. Tumor necrosis factor receptor 2 signaling induces selective C-IAP1-dependent ASK1 ubiquitination and terminates mitogenactivated protein kinase signaling. J Biol Chem 2007; 282: 7777-7782.

67. Kuranaga E, Kanuka H, Igaki T, Sawamoto K, Ichijo H, Okano H et al. Reaper-mediated inhibition of DIAP1-induced DTRAF1 degradation results in activation of JNK in Drosophila. Nat Cell Biol 2002; 4: 705-710.
68. Grell M, Douni E, Wajant H, Löhden M, Clauss M, Maxeiner B et al. The transmembrane form of tumor necrosis factor is the prime activating ligand of the $80 \mathrm{kDa}$ tumor necrosis factor receptor. Cell 1995; 83: 793-802.

69. Huang DC, Hahne M, Schroeter M, Frei K, Fontana A, Villunger A et al. Activation of Fas by FasL induces apoptosis by a mechanism that cannot be blocked by $\mathrm{Bcl}-2$ or $\mathrm{Bcl}-\mathrm{xL}$. Proc Natl Acad Sci 1999; 96: 14871-14876.

70. Holler N, Tardivel A, Kovacsovics-Bankowski M, Hertig S, Gaide O, Martinon F et al. Two adjacent trimeric Fas ligands are required for Fas signaling and formation of a death-inducing signaling complex. Mol Cell Biol 2003; 23: 1428-1440.

71. Baccam M, Bishop GA. Membrane-bound CD154, but not CD40-specific antibody, mediates NF-kappaB-independent IL-6 production in B cells. Eur J Immunol 1999; 29: 3855-3866.

72. Micheau O, Tschopp J. Induction of TNF receptor I-mediated apoptosis via two sequential signaling complexes. Cell 2003; 114: 181-190.

73. Habelhah H, Takahashi S, Cho SG, Kadoya T, Watanabe T, Ronai Z. Ubiquitination and translocation of TRAF2 is required for activation of JNK but not of p38 or NF-kappaB. EMBO J 2004; 23: 322-332.

74. Wu CJ, Conze DB, Li X, Ying SX, Hanover JA, Ashwell JD. TNF-alpha induced C-IAP1/ TRAF2 complex translocation to a Ubc6-containing compartment and TRAF2 ubiquitination. EMBO J 2005; 24: 1886-1898.

75. Matsuzawa A, Tseng PH, Vallabhapurapu S, Luo JL, Zhang W, Wang H et al. Essential cytoplasmic translocation of a cytokine receptor-assembled signaling complex. Science 2008; 321: 663-668.

76. Urbé S. Ubiquitin and endocytic protein sorting. Essays Biochem 2005; 41: 81-98.

77. Vercammen D, Vandenabeele P, Declercq W, Van de Craen M, Grooten J, Fiers W. Cytotoxicity in L929 murine fibrosarcoma cells after triggering of transfected human p75 tumour necrosis factor (TNF) receptor is mediated by endogenous murine TNF. Cytokine 1995; 7: 463-470.

78. Grell M, Zimmermann G, Gottfried E, Chen CM, Grunwald U, Huang DC et al. Induction of cell death by tumour necrosis factor (TNF) receptor 2, CD40 and CD30: a role for TNF-R1 activation by endogenous membrane-anchored TNF. EMBO J 1999; 18: 3034-3043.

79. Fotin-Mleczek M, Henkler F, Samel D, Reichwein M, Hausser A, Parmryd I et al. Apoptotic crosstalk of TNF receptors: TNF-R2-induces depletion of TRAF2 and IAP proteins and accelerates TNF-R1-dependent activation of caspase-8. J Cell Sci 2002; 115 2757-2770.

80. Schneider P, Schwenzer R, Haas E, Muhlenbeck F, Schubert G, Scheurich $P$ et al. TWEAK can induce cell death via endogenous TNF and TNF receptor 1. Eur J Immunol 1999; 29: 1785-1792.

81. Vince JE, Silke J. TWEAK shall inherit the earth. Cell Death Differ 2006; 13: 1842-1844.

82. Schiemann B, Gommerman JL, Vora K, Cachero TG, Shulga-Morskaya S, Dobles M et al. An essential role for BAFF in the normal development of B cells through a BCMAindependent pathway. Science 2001; 293: 2111-2114.

83. Sasaki Y, Casola S, Kutok JL, Rajewsky K, Schmidt-Supprian M. TNF family member B cell-activating factor (BAFF) receptor-dependent and -independent roles for BAFF in B cell physiology. J Immunol 2004; 173: 2245-2252.

84. Benson MJ, Dillon SR, Castigli E, Geha RS, Xu S, Lam KP et al. Cutting edge: the dependence of plasma cells and independence of memory $B$ cells on BAFF and APRIL. J Immunol 2008; 180: 3655-3659.

85. Miosge LA, Blasioli J, Blery M, Goodnow CC. Analysis of an ethylnitrosourea-generated mouse mutation defines a cell intrinsic role of nuclear factor kappaB2 in regulating circulating B cell numbers. J Exp Med 2002; 196: 1113-1119.

86. Yamada T, Mitani T, Yorita K, Uchida D, Matsushima A, Iwamasa $\mathrm{K}$ et al. Abnormal immune function of hemopoietic cells from alymphoplasia (aly) mice, a natural strain with mutant NF-kappa B-inducing kinase. J Immunol 2000; 165: 804-812.

87. Gardam S, Sierro F, Basten A, Mackay F, Brink R. TRAF2 and TRAF3 signal adapters act cooperatively to control the maturation and survival signals delivered to $B$ cells by the BAFF receptor. Immunity 2008; 28: 391-401.

88. Xie P, Stunz LL, Larison KD, Yang B, Bishop GA. Tumor necrosis factor receptorassociated factor 3 is a critical regulator of $B$ cell homeostasis in secondary lymphoid organs. Immunity 2007; 27: 253-267.

89. Ahmed AU, Moulin M, Coumailleau F, Wong WW, Miasari M, Carter $\mathrm{H}$ et al. CARP2 deficiency does not alter induction of NF-kappaB by TNFalpha. Curr Biol 2009; 19: R15-R17; author reply R17-9.

90. Liao W, Xiao Q, Tchikov V, Fujita K, Yang W, Wincovitch S et al. CARP-2 is an endosome-associated ubiquitin ligase for RIP and regulates TNF-induced NF-kappaB activation. Curr Biol 2008; 18: 641-649.

91. Shembade N, Parvatiyar K, Harhaj NS, Harhaj EW. The ubiquitin-editing enzyme A20 requires RNF11 to downregulate NF-kappaB signalling. EMBO J 2009; 28: 513-522.

92. Tokunaga F, Sakata SI, Saeki Y, Satomi Y, Kirisako T, Kamei K et al. Involvement of linear polyubiquitylation of NEMO in NF-kappaB activation. Nat Cell Biol 2009; 11: 123-132.

93. Kirisako T, Kamei K, Murata $S$, Kato M, Fukumoto $H$, Kanie $M$ et al. A ubiquitin ligase complex assembles linear polyubiquitin chains. EMBO $J$ 2006; 25: 4877-4887. 
94. Lemaitre B, Hoffmann J. The host defense of Drosophila melanogaster. Annu Rev Immunol 2007; 25: 697-743.

95. Leulier F, Lhocine N, Lemaitre B, Meier P. The Drosophila inhibitor of apoptosis protein DIAP2 functions in innate immunity and is essential to resist Gram-negative bacterial infection. Mol Cell Biol 2006; 26: 7821-7831.

96. Bertrand MJ, Doiron K, Labbé K, Korneluk RG, Barker PA, Saleh M. Cellular inhibitors of apoptosis CIAP1 and CIAP2 are required for innate immunity signaling by the pattern recognition receptors NOD1 and NOD2. Immunity 2009; 30: 789-801.

97. Meylan E, Burns K, Hofmann K, Blancheteau V, Martinon F, Kelliher M et al. RIP1 is an essential mediator of Toll-like receptor 3-induced NF-kappa B activation. Nat Immunol 2004; 5: 503-507.

98. Cusson-Hermance N, Khurana S, Lee TH, Fitzgerald KA, Kelliher MA. Rip1 mediates the Trif-dependent Toll-like receptor 3 - and 4-induced NF-\{kappa\}B activation but does not contribute to interferon regulatory factor 3 activation. J Biol Chem 2005; 280 36560-36566.

99. Ermolaeva MA, Michallet MC, Papadopoulou N, Utermöhlen O, Kranidioti K, Kollias G et al. Function of TRADD in tumor necrosis factor receptor 1 signaling and in TRIF-dependent inflammatory responses. Nat Immunol 2008; 9: 1037-1046.
100. Pobezinskaya YL, Kim YS, Choksi S, Morgan MJ, Li T, Liu C et al. The function of TRADD in signaling through tumor necrosis factor receptor 1 and TRIF-dependent Toll-like receptors. Nat Immunol 2008; 9: 1047-1054.

101. Hitotsumatsu O, Ahmad RC, Tavares R, Wang M, Philpott D, Turer EE et al. The ubiquitin-editing enzyme A2O restricts nucleotide-binding oligomerization domain containing 2-triggered signals. Immunity 2008; 28: 381-390.

102. Kaiser WJ, Upton JW, Mocarski ES. Receptor-interacting protein homotypic interaction motif-dependent control of NF-kappaB activation via the DNA-dependent activator of IFN regulatory factors. J Immunol 2008; 181: 6427-6434.

103. Michallet MC, Meylan E, Ermolaeva MA, Vazquez J, Rebsamen M, Curran J et al. TRADD protein is an essential component of the RIG-like helicase antiviral pathway. Immunity 2008; 28: 651-661.

104. Conze DB, Albert L, Ferrick DA, Goeddel DV, Yeh WC, Mak T et al. Posttranscriptional downregulation of C-IAP2 by the ubiquitin protein ligase C-IAP1 in vivo. Mol Cell Biol 2005; 25: 3348-3356.

105. Conte D, Holcik M, Lefebvre CA, Lacasse E, Picketts DJ, Wright KE et al. Inhibitor of apoptosis protein cIAP2 is essential for lipopolysaccharide-induced macrophage survival. Mol Cell Biol 2006; 26: 699-708. 